\title{
A apropriação de tecnologias de gestão pela agricultura familiar no Vale do Caí
}

\author{
Douglas Ritt ${ }^{1}$ \\ Luana Barcelos ${ }^{1}$ \\ Rosane Bernardete Brochier Kist ${ }^{2}$ \\ Silvio Cezar Arend ${ }^{3}$ \\ Cidonea Machado Deponti ${ }^{3}$
}

\begin{abstract}
RESUMO: Este artigo refere-se ao projeto de pesquisa e de extensão denominado "O uso e a apropriação de TICs pela agricultura familiar no Vale do Caí - RS", financiado pelo edital do MCTI/CNPq. Tal projeto foi desenvolvido através de uma experiência de extensão piloto em Montenegro durante o período de três anos e, posteriormente, o mesmo foi ampliado incluindo-se o Vale do Caí - RS. O projeto conta com a parceria da EMATER/ASCAR-RS, do Sindicato dos Trabalhadores Rurais do município de Montenegro-RS; das escolas rurais situadas no Vale do Caí; de alunos dos cursos de graduação em Contábeis e Administração do Campus de Montenegro da UNISC e de doutorandos do Programa de Pós-Graduação em Desenvolvimento Regional (PPGDR) da UNISC. Este artigo apresenta os resultados relativos à extensão tecnológica desenvolvida durante o Projeto Piloto dentre os quais se identificou que os agricultores analisados possuem acesso às TIC. Por outro lado, verificou-se que há necessidade de domínio e de apropriação do conhecimento para a utilização mais intensiva das TIC, pois se identifica que o acesso ainda é superficial não levando à apropriação da tecnologia. Embora alguns agricultores já realizem algum tipo de anotação e de acompanhamento, esse processo ocorre de maneira simplista e, na maioria das vezes, sem que haja um controle ou apoio à tomada de decisão.
\end{abstract}

Palavras-chave: Desenvolvimento Regional. Tecnologias de Informação e Comunicação. Gestão Rural.

\begin{abstract}
This article refers to the research and extension project called "The use and appropriation of ICTs by family farms in Vale do Caí - RS", financed by the edict of MCTI/CNPq. Such a project was developed through a pilot extension experience in Montenegro during the three-year period, subsequently the empirical was extended to the Vale do Caí-RS. The project counts on the partnership of EMATER/ASCAR-RS, the Union of Rural Workers of the municipality of Montenegro-RS, rural schools located in Vale do Caí and students of the undergraduate courses in Accounting and Administration of the Campus of Montenegro/UNISC, of the doctoral students of the Postgraduate Program in Regional Development. This article presents the results related to the technological extension developed during the Pilot Project. Among the results obtained, the analyzed farmers have access to ICT. However, regarding the use of technology, it
\end{abstract}

\footnotetext{
${ }^{1}$ Alunos do Curso de Administração. Campus de Montenegro da Universidade de Santa Cruz do Sul UNISC.

2 Assistente Social, Mestra e Doutora em Serviço Social (PUCRS). Pós-Doutora DOCFIX (CAPES/FAPERGS) no Programa de Pós-Graduação em Desenvolvimento Regional da UNISC.

${ }^{3}$ Professores do Programa de Pós-Graduação em Desenvolvimento Regional na Universidade de Santa Cruz do Sul. <cidonea@unisc.br>
} 
was verified that there is still a need for mastery and knowledge appropriation for the more intensive use of ICTs, since access is superficial and not conducive to the appropriation of technology. Although some farmers already carry out some type of annotation and follow-up, they are simplistic and often disconnected from a process of control or support for decision-making.

Keywords: Regional Development. Information and Communication Technologies. Rural Management.

\section{INTRODUÇÃO}

Este artigo objetiva analisar a experiência de pesquisa e de extensão tecnológica realizada pelo Programa de Pós-Graduação em Desenvolvimento Regional através do Projeto "O uso e a apropriação de tecnologias pela agricultura familiar no Vale do CaíRS” financiado pelo MCTI/CNPq, FAPERGS e UNISC, desenvolvido em parceria com a EMATER/ASCAR-RS, o Sindicato dos Trabalhadores Rurais e algumas Escolas Rurais do Vale do Caí.

Para tanto, utilizou-se de abordagem descritivo-analítica e da observação durante o período de quatro anos (2012 a 2016) de realização do Projeto. Inicialmente o projeto foi desenvolvido no formato de "Piloto" somente no município de Montenegro-RS e envolveu 10 famílias de agricultores familiares. Posteriormente, a partir da aprovação via Edital Universal MCTI/CNPq houve a possibilidade de expansão da experiência de pesquisa e de extensão abrangendo o Vale do Caí.

A equipe do projeto se caracteriza como interdisciplinar, pois agrupa professores e acadêmicos de diversas áreas do conhecimento, dentre elas a economia, a administração, o serviço social, a contabilidade e os sistemas de informação. Para a realização das atividades de pesquisa foram aplicados questionários semiestruturados junto a 370 agricultores familiares com o objetivo de identificar o seu perfil socioeconômico e o processo de uso e de apropriação de TIC. Neste artigo apresenta-se uma análise das atividades de extensão desenvolvidas por meio do projeto, tanto na modalidade como Piloto quanto na atual, contemplando os seguintes aspectos:

a) oficina de integração com os agricultores sobre a utilização das principais tecnologias de informação e de comunicação, especialmente o uso da internet, e-mail, acesso a sites, comunicadores instantâneos e demais funcionalidades básicas existentes. Esta oficina foi realizada no laboratório de informática da Universidade de Santa Cruz do 
Sul (UNISC), Campus de Montenegro, e possibilitou aos agricultores o acesso aos computadores e às principais tecnologias de informação e de comunicação, tais como o uso da Internet, e-mail, acesso a sites e comunicadores instantâneos.

b) realização de oficina de integração com palestra sobre a importância da educação financeira e do controle dos gastos;

c) construção de planilhas eletrônicas (Excel), de forma coletiva, visando facilitar o processo de gestão da propriedade e dos custos de produção através do acesso às informações sobre o estabelecimento rural, do acompanhamento das principais variáveis econômicas e da evolução das propriedades, contribuindo, desta forma, para a tomada de decisão. Nesta fase, os agricultores que apresentaram maior domínio sobre o uso de tais tecnologias contribuíram no processo de multiplicação do hábito de sua utilização junto às famílias dos demais agricultores participantes do projeto;

d) acompanhamento dos agricultores in loco visando o monitoramento e o auxílio no registro das informações, processo realizado pelos bolsistas e integrantes do projeto. Através do projeto pretende-se construir uma metodologia juntamente com os agricultores, de forma que estes possam tornar-se autônomos nos processos gerenciais. A introdução dessas tecnologias de informação e de comunicação é realizada a partir de diálogos, de discussões, de negociação e de construção conjunta do conhecimento, buscando-se o estabelecimento de uma dinâmica de interface e de aprendizagem social;

e) realização de palestras sobre temas relacionados com as perspectivas de mercado, os custos de produção, a gestão financeira e contábil da propriedade rural. Para tanto, foram convidados palestrantes externos que contribuíram no processo de discussão e compreensão sobre o mercado de citros, cultura predominante na região.

Através deste artigo pretende-se analisar como foram desenvolvidas estas atividades destacando-se os desafios e as dificuldades encontradas, bem como, a sua importância para as famílias de agricultores analisados e para o Vale do Caí-RS, reiterando-se o compromisso da universidade com o desenvolvimento da região.

$\mathrm{O}$ artigo está dividido em três seções, além da introdução e da conclusão. $\mathrm{Na}$ primeira seção apresenta-se o empírico e discute-se brevemente a caracterização do Vale do Caí. Na segunda seção aborda-se o problema teoricamente. Na terceira seção trata-se da experiência de extensão tecnológica a partir de dois itens, um primeiro, que se apresenta sobre as oficinas de integração e um segundo que aborda a gestão da 
propriedade rural pela agricultura familiar. Ao final, apresentam-se as considerações sobre o tema.

\section{APROPRIAÇÃO DE TECNOLOGIAS DE GESTÃo}

Inicialmente faz-se necessário esclarecer qual a compreensão teórica que se utiliza sobre a TIC. De acordo com CETIC (2016), TIC pode ser representada pela televisão, rádio, telefone fixo, console de jogo/videograme, TV por assinatura, antena parabólica, computador de mesa, computador portátil, tablet e telefone celular. Compreende-se que a TIC engloba as tecnologias de informação e de comunicação, uma vez que medeiam as relações comunicacionais entre as pessoas. Nesse sentido, na presente pesquisa consideraram-se como referidas tecnologias a televisão, o rádio, o telefone fixo, o telefone celular, o computador de mesa, o notebook e o tablet. Além disso, considerou-se o acesso à internet e a utilização de livros, jornais, revistas.

Ressalta-se também a compreensão e a diferenciação que se utiliza entre uso e apropriação de TIC, pois,

[...] os usos das TIC se referem à utilização dessas tecnologias, tais como o celular, o computador, a Internet, na vida cotidiana possibilitando a comunicação e a troca de informações. Já as apropriações constituem-se em maior domínio dessas tecnologias, ou seja, referem-se ao processo de sua utilização para além da troca de informação, para a qualificação dos processos de gestão, de controle da propriedade e para ampliação da interação com os demais agricultores e organizações vinculadas ao rural. Dessa forma, quanto maior a apropriação das TICs, maior a inclusão digital do meio rural (DEPONTI; FELIPPI; DORNELES, 2015, p. 10)

Tal compreensão aproxima-se com a referência do CETIC (2016, p.37) de que a apropriação das TIC consiste em "[...] um processo dinâmico e social, não um ato isolado de provisão de equipamentos e conteúdo". Essa afirmação permite entender a dissonância entre a disseminação do uso e a apropriação das TIC.

Segundo Pedroso (1999) a tecnologia pode ser classificada a partir de categorias: a) tecnologia de processo; b) tecnologia de materiais; c) tecnologia de produtos e serviços; d) tecnologia da informação; e, e) tecnologia de gestão. Neste artigo será dada mais ênfase às tecnologias de informação e de gestão, consideradas como aquelas que mais podem contribuir para o desenvolvimento das propriedades rurais. 
Abordar-se-ão as tecnologias de gestão a partir de uma análise empírica sobre as oficinas de integração realizadas através do Projeto Piloto referido, explicitando-se elementos sobre os processos de gestão da propriedade rural. Inicialmente se ressalta o conceito de gestão rural com base em Pelegrini e Gazola (2008, p. 155) que a definem como um

[...] processo em que o agricultor administra da melhor forma possível o seu empreendimento, combinando, para isso, os recursos disponíveis como a força de trabalho familiar, os recursos econômicos, os conhecimentos técnicoprodutivos, o capital social, os seus recursos naturais, etc para obter os melhores resultados e desenvolver de forma sustentável a sua unidade de produção e de processamento de alimentos.

Compreende-se que a gestão rural envolve não somente os aspectos vinculados ao controle contábil e gerencial, mas à propriedade como um todo, como os aspectos econômicos, financeiros, administrativos, ambientais e sociais que qualificam a tomada de decisão. Dessa forma, a gestão contábil e gerencial engloba o controle de despesas e de receitas a partir de fluxo de caixa, a informações mais detalhadas sobre renda bruta, renda líquida, índices de eficiência econômica e custos de produção.

\section{PRESSUPOSTOS METODOLÓGICOS}

As reflexões aqui apresentadas fazem parte do projeto de pesquisa e de extensão tecnológica denominado "O uso e a apropriação de tecnologias pela agricultura familiar no Vale do Caí-RS”, conforme já referenciado. Este projeto foi financiado pelo MCTI/CNPq, FAPERGS e UNISC e tem como objetivo Analisar o uso e a apropriação de tecnologias de informação e de comunicação para a agricultura familiar no Vale do Caí.

Em relação aos procedimentos metodológicos adotados, ressalta-se que a pesquisa teve abordagem qualitativa e as atividades de extensão contemplaram oficinas, palestras e a elaboração conjunta de planilhas de gestão das propriedades rurais, conforme será apresentado na terceira seção deste artigo.

O referido projeto foi desenvolvido no Corede Vale do Caí que, de acordo com a Fundação Econômica e Estatística (FEE, 2016), localiza-se ao Nordeste do RS, próximo à capital do estado e apresenta uma área de $1.854,4 \mathrm{~km}^{2}$. A título de planejamento o mesmo é formado por 19 municípios, que juntos totalizam 169.580 habitantes (IBGE, 2010). Destes, 124.897 (73,65\%) residem na área urbana e 26.34\% na área rural. 
Figura 1: Corede Vale do Caí-RS

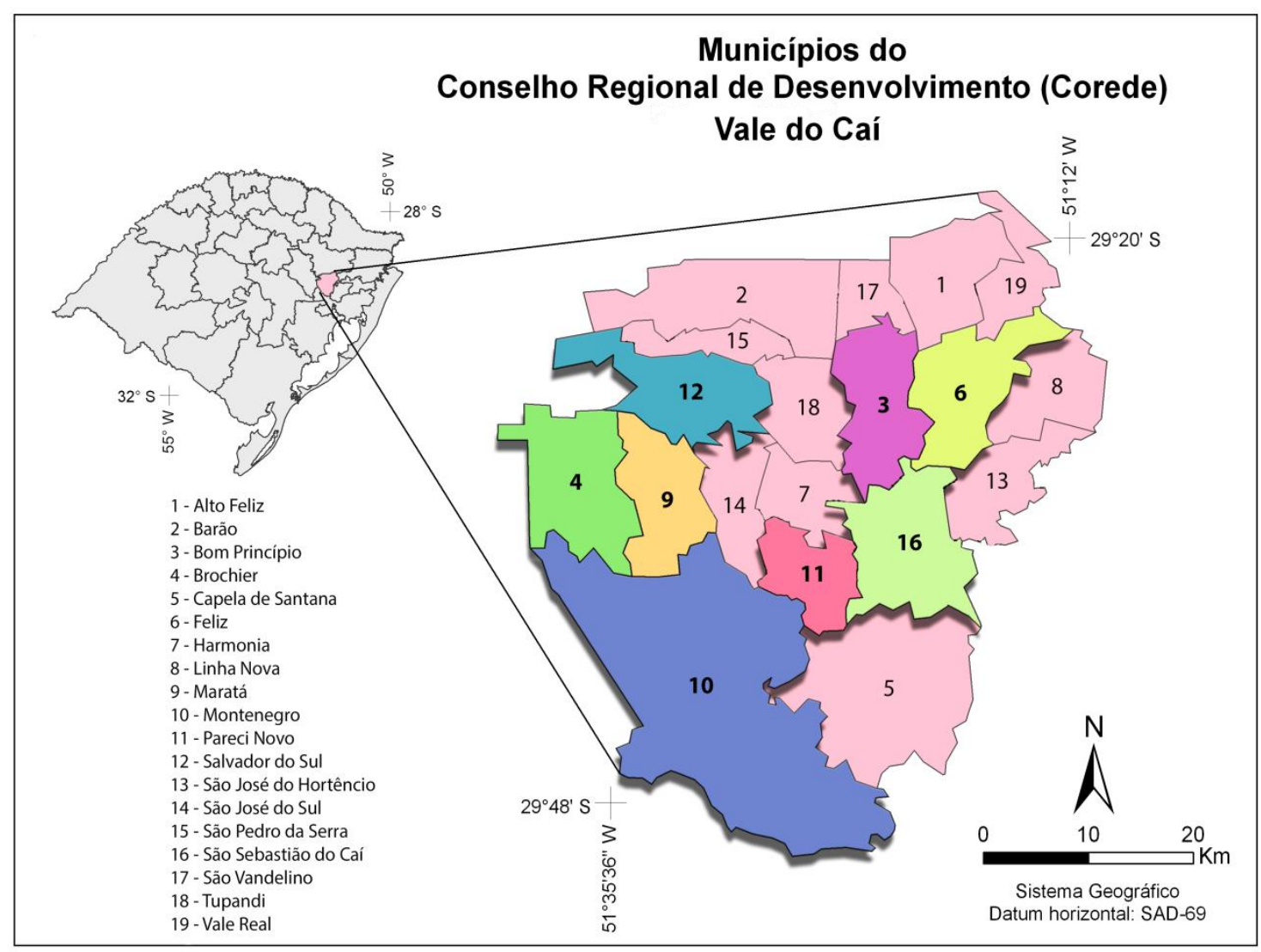

Fonte: Modificado de IBGE (2016).

A região Vale do Caí possui uma Densidade Demográfica de 93,9 hab $/ \mathrm{km}^{2}$, uma Taxa de analfabetismo de pessoas com 15 ou mais anos de idade de 3,06 \% e um Produto Interno Bruto ${ }^{4}$ de R $\$ 5.527 .808$ bilhões. Sendo que, do montante total, 2.695.911,96 $(48,77 \%)$ são provenientes do setor de prestação de serviços, 1.628.492,23 (29.46\%) da indústria e 1.203.403,80 (21,76\%) da agropecuária.

Constata-se que o PIB da região do Vale do Caí não é essencialmente oriundo da agropecuária, mesmo sendo tradicionalmente um território marcado pela produção agrícola. Impera no PIB a prestação de serviços e o ramo industrial. Todavia, não se pode desconsiderar a hipótese de que os elevados percentuais da prestação de serviço e da indústria, perante o percentual da agropecuária no PIB da referida região, podem estar diretamente relacionados com o aspecto da agropecuária.

${ }^{4} \mathrm{PIB} \quad$ (2012). Disponível em: <http://www.fee.rs.gov.br/wp-content/uploads/2015/12/20151217pibmunicipal-total-per-capita-2013.xlsx>. Acesso em: 08 dez. 2016. 
Em relação ao Índice de Desenvolvimento Humano Municipal (IDHM), segundo a classificação do PNUD ${ }^{5}$, apenas dois dos 19 municípios estão no ranking dos 100 municípios do RS com melhor IDHM, Montenegro e São Vendelino. Montenegro, por exemplo, ocupa a octogésima sétima $\left(87^{\circ}\right)$ posição, com IDHM de 0,755 , já o município de São Vendelino ocupa a octogésima nona $\left(89^{\circ}\right)$ posição, com IDHM de 0,754 . Os dois municípios com baixo IDHM são Capela de Santana e Maratá ocupando, respectivamente, a $\left(433^{\circ}\right)$ posição, com IDHM de 0,661 e a $\left(326^{\circ}\right)$ posição, com 0,697 IDHM. Esta realidade evidencia que há uma heterogeneidade de desenvolvimento entre os municípios do Vale do Caí, sendo que estes, no contexto geral, apresentam baixos índices de desenvolvimento humano.

Para a realização da coleta de dados primários foram realizadas entrevistas com 375 agricultores familiares utilizando-se formulários semiestruturados que possibilitaram a identificação do perfil dos agricultores analisados e a compreensão de questões relativas ao uso e a apropriação das TIC. Essas informações foram tabuladas através do Programa Statistical Package for Social Sciences (SPSS), mas ressalta-se que as atividades de pesquisa não serão analisadas neste artigo, pois o mesmo terá como foco as atividades de extensão tecnológica.

No conjunto de atividades previstas no projeto posteriormente foram realizadas oficinas de integração que possibilitaram a capacitação dos agricultores sobre a importância do uso de tecnologias de gestão na propriedade rural e a elaboração conjunta de planilhas de acompanhamento e de controle da propriedade rural. Foram realizadas quatro oficinas de integração no Campus de Montenegro da UNISC entre os anos de 2012 e 2015, durante a realização do Projeto Piloto. No projeto atual, financiado pelo $\mathrm{CNPq} / \mathrm{MCTI}$, as oficinas de integração vinculadas às atividades de extensão tecnológica serão realizadas em 2017. Está prevista a realização de quatro oficinas de integração sobre os seguintes temas: uso de mídias, educação financeira, controle e registro de informações gerenciais e financeiras, e custos de produção.

\footnotetext{
${ }^{5}$ IDHM por município. Disponível em: <http://www.atlasbrasil.org.br/2013/pt/ranking>. Acesso em: 09 nov. 2016.
} 


\section{A EXPERIÊNCIA DE EXTENSÃo TECNOLÓGICA NO VALE DO CAÍ, RS}

Ressalta-se a importância do desenvolvimento deste projeto de pesquisa e de extensão a partir do PPGDR/UNISC em municípios do Vale do Caí, o que revela a preocupação da universidade com o desenvolvimento da região. Identifica-se que a produção do conhecimento pressupõe a relação dialética entre o ensino, a pesquisa e a extensão de modo a garantir que todo o conhecimento produzido, tanto no âmbito da pesquisa como do ensino, deve estar diretamente relacionado com os interesses da sociedade.

Nesse sentido, uma experiência de extensão tecnológica representa uma forma de intervenção realizada por determinados atores em uma realidade concreta. No caso do projeto ora analisado esse processo ocorre através da intervenção de uma equipe de alunos, de professores, de pesquisadores e de demais atores da sociedade em um ambiente de agricultura familiar no Vale do Caí. Especificamente, nas formas de gestão da propriedade rural, mediadas por de tecnologias de gestão. Estas últimas se caracterizam por planilhas, softwares, cálculos de demonstração de resultados, de custos de produção que auxiliam na tomada de decisão.

Com base nesta premissa, neste item serão apresentados alguns elementos identificados através do processo de extensão referido. Inicialmente será apresentado o processo metodológico de realização das oficinas, seguido de uma análise com base em alguns resultados obtidos através da experiência de extensão tecnológica desenvolvida junto aos agricultores familiares do Vale do Caí.

\subsection{As oficinas de integração}

As oficinas de integração se constituíram em momentos de interação e de participação envolvendo toda a equipe do projeto e os agricultores componentes. As oficinas foram compostas por atividades como a apresentação da equipe, dos agricultores, e das organizações envolvidas; o conhecimento do projeto tendo-se em vista a apropriação dos agricultores sobre os objetivos do mesmo; e a realização das oficinas propriamente ditas. A primeira oficina teve como tema a educação financeira, a segunda abordou o uso de mídias, a terceira foi sobre o controle gerencial e a quarta tratou sobre 
custos de produção. Além das oficinas de integração também foram realizadas palestras sobre temas sugeridos pelos próprios agricultores.

Durante a realização das oficinas foram identificados alguns desafios para sua operacionalização, dentre os quais se destaca a dificuldade de organizar um horário que permitisse a presença de todos os agricultores participantes do Projeto, uma vez que as atividades cotidianas e o grande número de ações nas quais estes agricultores estão envolvidos exigiram da equipe um esforço em ajustar os horários. Esta dificuldade gerou a necessidade de se realizar contato telefônico prévio com os agricultores antes da realização da oficina. Foram contatados os agricultores que manifestaram interesse em participar das atividades de extensão quando da realização do roteiro semiestruturado, instrumento utilizado na fase da pesquisa. A participação dos agricultores foi restrita, ou seja, menor do que a esperada, de modo geral, em todas as atividades de extensão realizadas. No entanto, aqueles que participaram das oficinas demonstraram interesse, especialmente no que se refere à qualificação da gestão de suas propriedades e ao controle dos custos.

A equipe realizou várias discussões e reflexões sobre a melhor maneira de se abordar as temáticas desenvolvidas e também, por diversas vezes, questionou-se sobre a ausência ou desinteresse por parte dos agricultores. Os agricultores inicialmente se apresentaram receosos, preocupados e desconfiados, especialmente porque esta atividade de registro das informações não era uma atividade do cotidiano deles e a maioria não possuía o hábito de fazer registros. Em segundo lugar, pelo fato de muitos deles não compreenderem como esta prática poderia ajudá-los no futuro para a gestão da propriedade e para a tomada de decisão, apesar das explicações repassadas pela equipe do projeto. Em terceiro lugar, muitos deles possuíam medo/receio de se expor ou de que as informações sobre suas propriedades estivessem ao acesso dos demais participantes (DEPONTI, 2014).

Tal reflexão levou a equipe a buscar outras estratégias para a operacionalização do projeto, a partir do qual se optou pelo seu processo de divulgação na mídia, especialmente através de jornal, rádio e TV. Além disso, os agricultores foram agrupados separando-se aqueles que de fato possuíram interesse na gestão rural e os demais. Dessa forma, as oficinas de gestão rural foram realizadas para o grupo de agricultores que já possuíam compreensão sobre sua importância e que manifestavam tal interesse. Para os demais foram realizadas atividades de acordo com suas demandas privilegiando outras 
temáticas. Esta ação buscou aproximar os objetivos do projeto aos objetivos dos agricultores, o que possibilitou um processo de construção coletiva da aprendizagem e do conhecimento.

Conforme já destacado por Deponti (2014, p.18-19)

[...] o processo apresentou-se mais complexo do que previsto inicialmente, pois embora algumas estratégias de integração fossem realizadas, a construção da intimidade e da confiança entre os membros da equipe não ocorreu simultaneamente às atividades desenvolvidas. Além disso, o sentimento de pertencimento por parte dos agricultores é algo a ser construído, que acontece de forma processual, de acordo com a participação deles e com a compreensão sobre a importância e a necessidade de serem realizadas mudanças no processo de gestão da propriedade. Portanto, embora convidados a participar, muitas vezes não o fazem porque tal atividade não se coloca como imprescindível e porque eles não possuem compreensão da importância dos registros, além de que, não vivenciam, no cotidiano, a utilidade dos instrumentos para a tomada de decisão.

Constata-se que o processo de intervenção realizado junto aos agricultores familiares através do projeto de extensão tecnológica possibilitou a compreensão sobre a necessidade de se considerar as particularidades concretas de todos os agricultores, pois eles não podem ser analisados sob um mesmo patamar na medida em que se identificam diferenças no que tange aos sistemas de sentido, de significados e, especialmente, com relação as suas condições objetivas de vida.

\subsection{A gestão da propriedade rural pelos agricultores familiares}

No tocante às oficinas de gestão se destaca que elas começaram com a distribuição de um caderno de anotações, uma agenda, em que os agricultores registravam todas as despesas e as receitas da propriedade e da família. Esta iniciativa foi realizada porque, em geral, os agricultores não separam as contas relativas à produção das contas referentes ao grupo familiar, pois a família está intimamente ligada à propriedade. Também foram repassadas caixas para que os agricultores colocassem todas as notas referentes aos gastos realizados. Identificaram-se alguns agricultores que já utilizavam algum tipo de controle ou registro das informações e solicitou-se que eles compartilhassem tais instrumentos utilizados com os demais. No entanto, verificou-se que havia muita dificuldade de compartilhamento das informações, pois os agricultores se apresentavam desconfiados em função de que estavam preocupados com o destino que 
seria dado a tais informações. Desenvolveram-se também planilhas em Excel especificando-se as entradas e as saídas para registro das informações, cartilhas de orçamento familiar e caderno de gestão e de controle da propriedade rural, desenvolvidos pela equipe do projeto. Estas planilhas foram oferecidas também em papel, contudo, não foram introduzidas no cotidiano dos agricultores. A equipe acredita que as cartilhas e os softwares utilizados no mercado não se coadunam com a realidade do agricultor, conforme já mencionado por Deponti (2014, p. 11) que salienta que há "descompasso entre inúmeros softwares e ferramentas de gestão e o baixo uso por parte dos agricultores, aliado à desconexão das ferramentas existentes com a capacidade e a necessidade dos agricultores".

Evidencia-se a existência de uma heterogeneidade da agricultura familiar, seja em termos de disponibilidade de recursos, de acesso aos mercados, de capacidade de geração de renda e de acumulação, quanto ao grau de escolaridade, à composição familiar e à diversidade produtiva das propriedades no tocante ao tamanho, aos tipos de cultivo e de criações, características que dificultam a generalização de um modelo de gerenciamento que seja compatível com as distintas características. (DEPONTI, 2014).

De acordo com a pesquisa constatou-se que as formas de controle e de gerenciamento disponíveis não captam a diversidade e a particularidade da gestão rural das propriedades pela agricultura familiar. Dessa forma, a equipe do projeto desafiou-se a construir coletivamente alternativas de gestão e de controle mais apropriados pelos agricultores, uma vez que tais registros foram acompanhados pela visita in loco às propriedades realizada pelos bolsistas e pesquisadores.

Ressalta-se que os resultados desta atividade ainda não são conclusivos, pois embora o referido projeto esteja sendo executado há quatro anos, este processo ainda não está concluso. Entretanto, é possível observar que esta estratégia se apresentou mais efetiva no que se refere ao desenvolvimento do sentimento de pertencimento e de valorização do "saber-fazer" dos agricultores. No entanto, destaca-se que a situação descrita exige um horizonte de longo prazo, de maturação e de entrosamento da equipe com os demais participantes, de recursos financeiros, de paciência quanto aos resultados, pois o processo avança e retrocede a todo o momento. Evidencia-se ainda que estas características não se assemelham aos objetivos das políticas públicas e dos projetos de pesquisa e de extensão financiados pelas diversas organizações que apresentam prazo definido, objetivos específicos, resultados esperados, metas alcançadas. 


\section{ALGUMAS CONSIDERAÇÕES E REFLEXÕES SOBRE O TEMA}

A intervenção realizada a partir das oficinas de extensão apresentou resultados positivos já que houve maior inter-relação entre a universidade e a comunidade montenegrina, na medida em que os agricultores se aproximaram da universidade e viram nela uma possibilidade de contribuição. A equipe, por sua vez, conheceu o rural do município e conviveu de forma mais próxima as suas mazelas e belezas, sentindo-se desafiada a qualificar os processos de intervenção. Estes resultados confirmam que a produção do conhecimento somente é possibilitada através da articulação entre o conhecimento científico dos professores, dos alunos e dos parceiros envolvidos no processo, em conjunto com o conhecimento dos próprios agricultores, adquiridos ao longo de suas trajetórias de vida, resultando, assim, na construção de um conhecimento híbrido que é obtido através da interface social.

Por outro lado, identificaram-se várias dificuldades no tocante aos processos de gestão da propriedade pela agricultura familiar, tais como: o tempo necessário para integração da equipe com os agricultores, a complexidade dos softwares de gestão rural disponíveis no mercado, a inadequação desses softwares a realidade da agricultura familiar, a falta de registro das entradas e saídas pelos agricultores. O Projeto confirmou a indicação da literatura de que não há uma cultura de registro de informações por parte dos agricultores, associada à inadequação das ferramentas existentes, de difícil compreensão devido ao baixo grau de instrução dos sujeitos envolvidos e da complexidade do processo de gestão da propriedade rural. Conclui-se ainda que há necessidade de construção de formas/alternativas/instrumentos que deem conta de tal situação frente ao mercado, pois a partir do sistema capitalista se tornam necessários processos mais adequados à realidade concreta.

Constata-se ainda que há muitos desafios com relação às atividades de pesquisa e de extensão tecnológicas propostas através do projeto referido, pois se reconhece que algumas delas ainda apresentem um distanciamento entre a práxis e o cotidiano dos agricultores. Nesse sentido, torna-se fundamental a identificação desta realidade para que se possa, através da pesquisa, compreender a realidade concreta de forma a qualificar os processos interventivos através das atividades de extensão. 
Assim, conclui-se que o referido projeto possui uma relevância social na medida em que possibilita através da articulação entre o ensino, a pesquisa e a extensão, a produção do conhecimento e a contribuição do PPGDR da UNISC com o desenvolvimento do "Território do Citros" através do envolvimento de alunos e de professores da graduação, da pós-graduação, da comunidade local, de organizações sociais como o Sindicato de Trabalhadores Rurais e de órgãos governamentais como a EMATER/RS-ASCAR.

\section{REFERENCIAS}

CETIC. Pesquisa sobre o uso das tecnologias de informação e comunicação nos domicílios brasileiros [livro eletrônico]: TIC domicílios 2015. São Paulo: Comitê Gestor da Internet no Brasil, 2016. Disponível em <http://cetic.br/pesquisa/domicilios/>. Acesso em: 31 mai. 2017.

DEPONTI, C. M. As “agruras" da gestão da propriedade rural pela agricultura familiar. REDES, Santa Cruz do Sul, v. 19, ed. especial, p. 9-24, 2014. Acesso em: 31 de mai. 2017. DOI: http://dx.doi.org/10.17058/redes.v19i2014.5150

DEPONTI, C. M.; KIST, R.B.B.; AREND, S. Desenvolvimento regional e agricultura familiar: o uso e a apropriação das Tics no Vale do Caí - RS. Desenvolvimento Regional em debate, v. 5, n. 2, p. 170-187, jul./dez. 2015. Disponível em: <https://dialnet.unirioja.es/descarga/articulo/5443888.pdf.> Acesso em: 31 mai. 2017.

DEPONTI, C. M., FELIPPI, A. C. T., DORNELLES, M. Os usos e as apropriações das Tics na agricultura familiar em regiões do sul do Brasil. Anais do VII Seminário Internacional sobre Desenvolvimento Regional. Globalização em Tempos de Regionalização - Repercussões no Território, Santa Cruz do Sul, RS, Brasil, 2015. Disponível em: <http://online.unisc.br/acadnet/anais/index.php/sidr/article/view/13368/2534>. Acesso em 31 mai. 2017.

FEE. Disponível em: <http://www.fee.rs.gov.br/wpcontent/uploads/2015/12/20151217pib-municipal-total-per-capita-2013.xlsx>. Acesso em: 08 dez. 2016.

IBGE. Censo Demográfico. Brasília: Gov. Federal, 2010. Disponível em: Censo 2010. <http://www.censo2010.ibge.gov.br/sinopse/index.php?dados=29\&uf=43>. Acesso em: 09 abr. 2016.

IBGE. Cidades. 2016. Disponível em: <http://www.cidades.ibge.gov.br>. Acessado em: 09 de Abril de 2016.

IDHM por município. Disponível em: <http://www.atlasbrasil.org.br/2013/pt/ranking>. Acesso em: 09 abr. 2016. 
PEDROSO, M. C. Uma metodologia de análise estratégica da tecnologia. Gestão \& Produção. São Carlos, v.6, n.1, p. 61-76, 1999. Disponível em: <http://www.scielo.br/pdf/gp/v6n1/a05v6n1>. Acesso em 31 de mai. 2017.

PELEGRINI, G.; GAZOLLA, M. A. AGROINDÚSTRIA FAMILIAR NO RIO GRANDE DO SUL: Limites e potencialidades a sua reprodução social. Frederico Westphalen: Editora da URI, 2008.

Como citar este documento: RITT, Douglas et al. A apropriação de tecnologias de gestão pela agricultura familiar no Vale do Caí. Revista Jovens Pesquisadores, Santa Cruz do Sul, v. 7, n. 1, jan. 2017. ISSN 2237-048X. Disponível em: $<$ https://online.unisc.br/seer/index.php/jovenspesquisadores/article/view/8871>. Acesso em: ... doi: http://dx.doi.org/10.17058/rjp.v7i1.8871. 